\title{
Laryngeal mask airway cuff pressure and position during anaesthesia lasting one to two hours
}

The cuff of the laryngeal mask airway (LMA) is highly permeable to nitrous oxide $\left(\mathrm{N}_{2} \mathrm{O}\right)$, and cuff pressure increases during $\mathrm{N}_{2} \mathrm{O} / \mathrm{O}_{2}$ anaesthesia. The extent of these changes and their effect on LMA position have previously only been investigated for short procedures. The current study was designed to investigate the effects of nitrous oxide-oxygen $\left(\mathrm{N}_{2} \mathrm{O} / \mathrm{O}_{2}\right)$ anaesthesia lasting one to two hours on cuff pressure, LMA positioning and pharyngeal morbidity. Twenty-four male patients underwent spontaneous ventilation anaesthesia with $66 \% \mathrm{~N}_{2} \mathrm{O}$ in oxygen and isoflurane. Following insertion and inflation of a \#4 LMA with $30 \mathrm{ml}$ air, mean (SD) cuff pressures immediately increased from 107 (9) to 145 (12) $\mathrm{mmHg}$ and then at a decreasing rate for $90 \mathrm{~min}$ to peak at 215 (12) $\mathrm{mmHg}$. There was a correlation between $\mathrm{N}_{2} \mathrm{O}$ concentration and final cuff volume $(P<0.001)$. There was no displacement of the LMA cuff in any patient. Three of 19 patients had a mild sore throat. This study demonstrates that the increase in LMA cuff pressure is self limiting over a one-to-two-hour period and does not cause displacement of the LMA. There is no evidence that cuff pressure monitoring and pressure limitation is necessary during LMA anaesthesia.

Le coussinet du masque laryngé (ML) est hautement perméable au protoxyde d'azote $\left(\mathrm{N}_{2} \mathrm{O}\right)$, et sa pression augmente pendant l'anesthésie au $\mathrm{N}_{2} \mathrm{O} / \mathrm{O}_{2}$. Limportance de ces changements et leur effet sur la position du ML n'ont été investigués précédemment que pour de courtes interventions. Cette étude propose dïnvestiguer les effets du mélange de protoxyde d'azote et d'oxygène $\left(\mathrm{N}_{2} \mathrm{O} / \mathrm{O}_{2}\right)$ sur la pression du coussinet au cours

\section{Key words}

ANAESTHETICS, GASES: nitrous oxide;

EQUIPMENT: laryngeal mask airway.

From the Department of Anaesthesia and Intensive Care,

Cairns Base Hospital, Cairns, Australia 4870, and the

Department of Anaesthesia*, Royal Berkshire Hospital,

London Rd., Reading, Berkshire RG1 SAN, United Kingdom.

Address correspondence to: Dr. J. Brimacombe.

Accepted for publication 6th April, 1994. d'une anesthésie d'une à deux heures, ainsi que sur la position du $M L$ et ses répercussions sur le pharynx. Vingt-quatre patients masculins sont soumis à une anesthésie en ventilation spontanée avec $66 \%$ de $\mathrm{N}_{2} \mathrm{O}$ dans l'oxygène et de l'isoflurane. Après linsertion et linflation d'un $M L \# 4$ avec $30 \mathrm{ml}$ d'air, les pressions moyennes (DS) du coussinet augmentent immédiatement de 107 (9) à 145 (12) $\mathrm{mm}$ de $\mathrm{Hg}$ et ensuite atteignent un pic de 215 (12) $\mathrm{mm}$ de $\mathrm{Hg}$ après une augmentation décroissante de 90 min. Il y a une corrélation entre la concentration de $\mathrm{N}_{2} \mathrm{O}$ et le volume final du coussinet $(P<0,001)$. Il n'y a eu de déplacement du coussinet du $M L$ chez aucun patient. Trois des 19 patients ont eu une douleur modérée de la gorge. Cette étude démontre que laugmentation de la pression du coussinet du ML se limite d'elle même après une période d'une à deux heures et ne provoque pas de déplacement du ML. Il n'y a pas d'argument indiquant que le monitorage de la pression du coussinet et sa limitation soient nécessaires au cours d'une anesthésie au $M L$.

The laryngeal mask airway (LMA) cuff is highly permeable to nitrous oxide $\left(\mathrm{N}_{2} \mathrm{O}\right)$, and the pressure of the air-filled LMA cuff increases during nitrous oxide/oxygen $\left(\mathrm{N}_{2} \mathrm{O} / \mathrm{O}_{2}\right)$ anaesthesia. ${ }^{1,2}$ It has been suggested that cuff pressures should be monitored and controlled during prolonged procedures ${ }^{1-4}$ to minimize pharyngeal morbidity and the frequency of adverse airway events. However, the incidence of associated problems and the extent of the pressure rise has not been formally studied for procedures lasting more than $\mathbf{4 0} \mathrm{min}$.

The current study was, therefore, designed to investigate the effects of prolonged nitrous oxide-oxygen $\left(\mathrm{N}_{2} \mathrm{O} / \mathrm{O}_{2}\right)$ anaesthesia on cuff pressure, cuff displacement and pharyngeal morbidity.

\section{Methods}

\section{Pre-clinical testing}

Eight \#4 LMAs were selected for inclusion in the clinical study. Each was checked for evidence of cuff herniation 
or cuff asymmetry and tested for macro-leaks by inflation and immersion in water for five minutes. To check for micro-leaks the spontaneous deflation pressure characteristics of each LMA was determined. The pilot tube was attached via a three-way tap to a pressure transducer which was calibrated and zeroed. The transducer dome was filled with fluid and the system took less than ten seconds to reach equilibrium following a pressure change. The LMA cuff was then suspended in air at $20^{\circ} \mathrm{C}$ and inflated with air to $200 \mathrm{mmHg}$ and the pressure recorded over five hours. The transducer was re-zeroed every hour and testing was conducted at sea level. In addition, the pressure volume curves for all LMAs were determined by inflation with $30-46 \mathrm{ml}$ air in $2 \mathrm{ml}$ increments from a baseline pressure of minus $25 \mathrm{mmHg}$. In vitro tests were performed before and after the clinical study.

\section{Clinical study}

Ethical committee approval was obtained, and each patient entering the trial gave informed consent. Twentyfour male patients aged 18-80 yr and of ASA status 1 or 2 were included in the study. All patients were scheduled for elective minor peripheral surgery expected to last for at least $90 \mathrm{~min}$. The exclusion criteria were a history of previous upper abdominal surgery, known or symptomatic hiatus hernia, oesophageal reflux, peptic ulceration and morbid obesity. All patients received a size 4 LMA, and each LMA was used three times.

The pilot tube of each LMA was attached via a threeway tap to a pressure transducer (vide supra) which was calibrated and zeroed and the cuff was evacuated to a baseline pressure of minus $25 \mathrm{mmHg}$. The cuff was then inflated in vitro with $30 \mathrm{ml}$ of air from a $50 \mathrm{ml}$ syringe and the pressure recorded with the LMA suspended in air at $20^{\circ} \mathrm{C}$. Immediately before insertion, the cuff was evacuated to baseline pressure.

All patients were premedicated with temazepam 10-20 $\mathrm{mg}$ one hour preoperatively. Anaesthesia was induced with fentanyl $1 \mu \mathrm{g} \cdot \mathrm{kg}^{-1}$ and propofol $2.5 \mathrm{mg} \cdot \mathrm{kg}^{-1}$ and the LMA was then inserted using the standard technique with the cuff fully deflated to baseline pressure. ${ }^{4}$ The cuff was then inflated with $30 \mathrm{ml}$ air. The system remained sealed after attachment of the $50 \mathrm{ml}$ syringe to the three-way tap.

The patient's head and neck were placed in the neutral position, and the LMA was attached to the anaesthetic breathing system below the chin. The LMA was supported, but remained unfixed with tape or tie. Function was assessed by gentle hand ventilation, synchronised expansion of the chest and capnography. The effectiveness of the seal was assessed by audible leak at the start and end of the procedure. Time zero was taken as $20 \mathrm{sec}$ after inflation of the cuff, and the cuff pressure was continuously monitored.

Anaesthesia was maintained with $1-2 \%$ isoflurane in $66 \% \mathrm{~N}_{2} \mathrm{O}$ and oxygen using a spontaneous ventilation technique via a circle anaesthetic breathing system with fresh gas flows of $6 \mathrm{~L} \cdot \mathrm{min}^{-1}$. Monitoring included ECG, indirect BP, pulse oximetry and nasopharyngeal temperature. Inspiratory and end-tidal gases were continuously analysed using a Datex AS/3 monitor. Care was taken to ensure that the LMA was not disturbed during surgery. Cuff gas volume was noted at the end of the procedure or after two hours by aspiration into the $50 \mathrm{ml}$ syringe until the baseline pressure was obtained, before the anaesthetic gases were switched off. The aspirated cuff gas was then injected into the gas inlet of the Datex AS/3 for analysis and the cuff reinflated with air for recovery. Immediately following insertion and again towards the end of the procedure, a fibreoptic scope was passed to the level of the mask aperture bars and the position of the LMA was scored using the following system: ${ }^{5} 4$, only cords seen; 3 , cords plus posterior epiglottis seen; 2 , cords plus anterior epiglottis seen; 1 , cords not seen. The presence or absence of the oesophagus was also noted. In addition, a mark was made on the LMA tube at the level of the teeth following insertion and any subsequent displacement noted. LMA insertion, fibreoptic scoring and assessment of function was conducted by one of the authors who is an experienced LMA user.

Twenty-four hours after surgery patients were interviewed to determine the incidence and severity of pharyngeal morbidity, including sore throat, hoarseness and dysphagia. Symptoms were scored as mild, moderate or severe. The data were analysed using linear regression and Student's $t$ test, and significance was taken as $P$ $<0.05$.

\section{Results}

\section{Pre-clinical testing}

No macro-leaks were detected. The spontaneous deflation characteristics of all LMAs used in the study were consistent both before and after the clinical study and indicated that there were no micro-leaks (Figure 1). Over the first two hours the spontaneous deflation rate was approximately $0.5 \mathrm{mmHg}$ per minute. This was consistent with the known permeability of the LMA cuff to nitrogen and oxygen. ${ }^{1}$ The pressure-volume curve is given in Figure 2.

\section{Clinical study}

The mean (range) for age and weight were 33.8 (18-59) $\mathrm{yr}$ and $78.3(56-110) \mathrm{kg}$. The median (range for fibreoptic scoring was 3.0. ${ }^{1-4}$ The mean time at which cuff gas was 


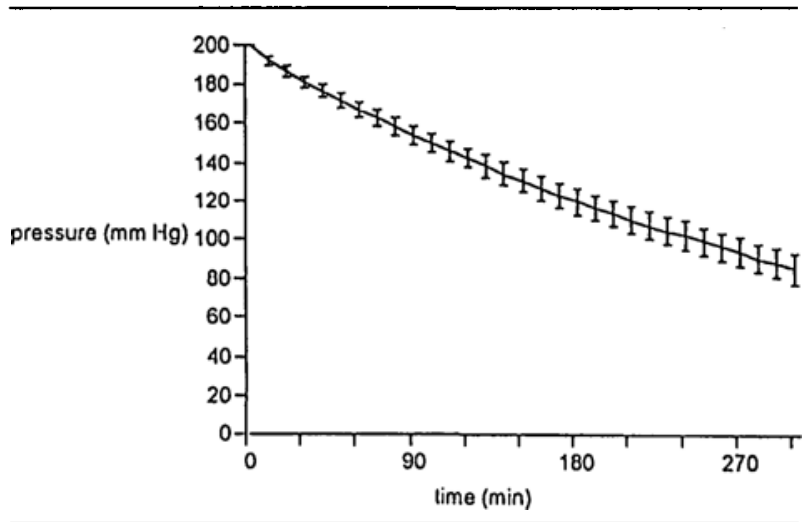

FIGURE 1 The spontaneous deflation characteristics of the LMAs in vitro. Mean (SD).

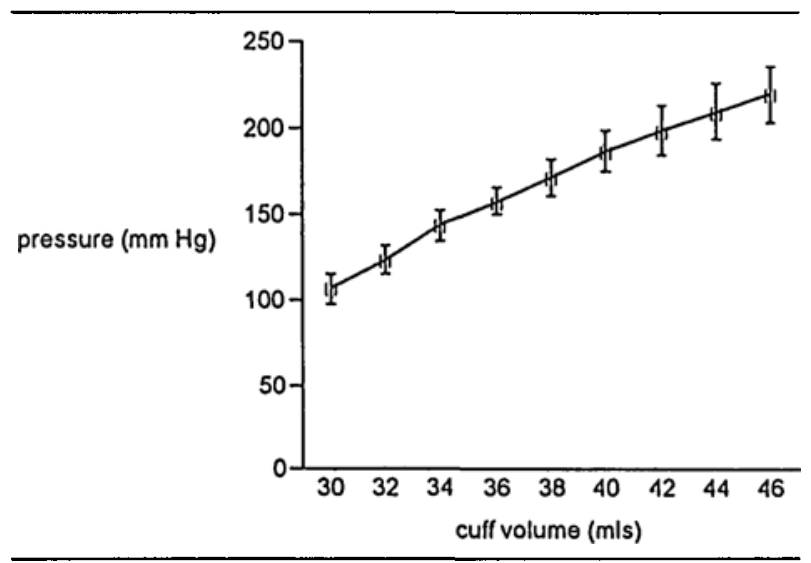

FIGURE 2 Pressure-volume curve for the LMAs in vitro. Mean (SD).

analysed was 77.5 (60-120) min. The LMA was successfully inserted in all patients within $20 \mathrm{sec}$, and functioned adequately in each case. The mean (range) leak pressure was $18(7-28) \mathrm{cm} \mathrm{H}_{2} \mathrm{O}$. There was no difference in audible leak pressure between the start and end of the procedure. All fibreoptic scores were identical at the beginning and end of the procedure and there was no evidence that the LMA was displaced. The oesophageal inlet was not seen either at insertion or towards the end of the procedure in any patient.

Following insertion and inflation, mean (SD, range) cuff pressures rose immediately from $107(9,92-128)$ to $145(12,126-187) \mathrm{mmHg}(\mathrm{t}$ test $-P<0.001)$ and then at a decreasing rate for $90 \mathrm{~min}$ to peak at 215 (12, 182-249) $\mathrm{mmHg}$ (Figure 3). The mean (range) final cuff volume was $39(32-44) \mathrm{ml}$, the mean final cuff pressure was 201 (167-248) $\mathrm{mmHg}$ and the mean nitrous oxide concentration was $24 \%$ (14-38). There was a correlation between nitrous oxide concentration and final cuff volume $\left(\mathrm{R}^{2} 0.603, \mathrm{t}\right.$ test $\left.-P<0.001\right)$ (Figure 4). The mean

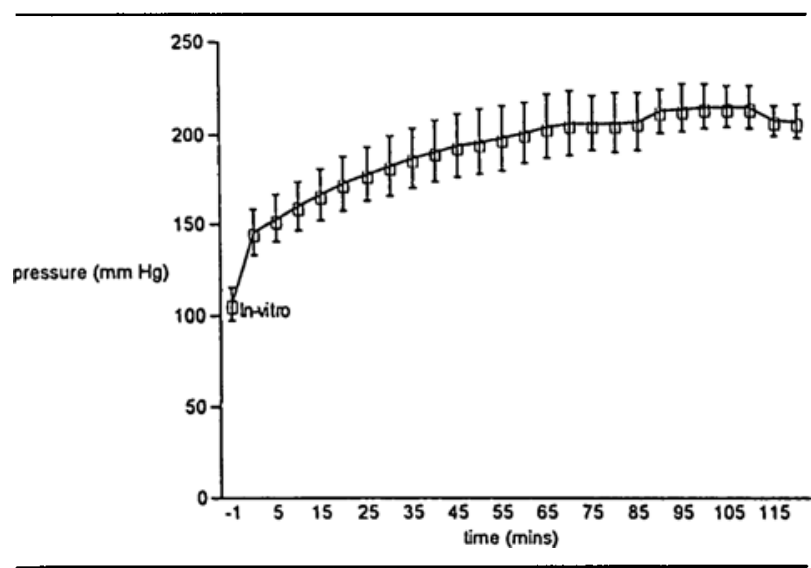

FIGURE 3 Cuff pressure changes in the air-filled cuff with time during $\mathrm{N}_{2} \mathrm{O} / \mathrm{O}_{2}$ anaesthesia. Mean (SD).

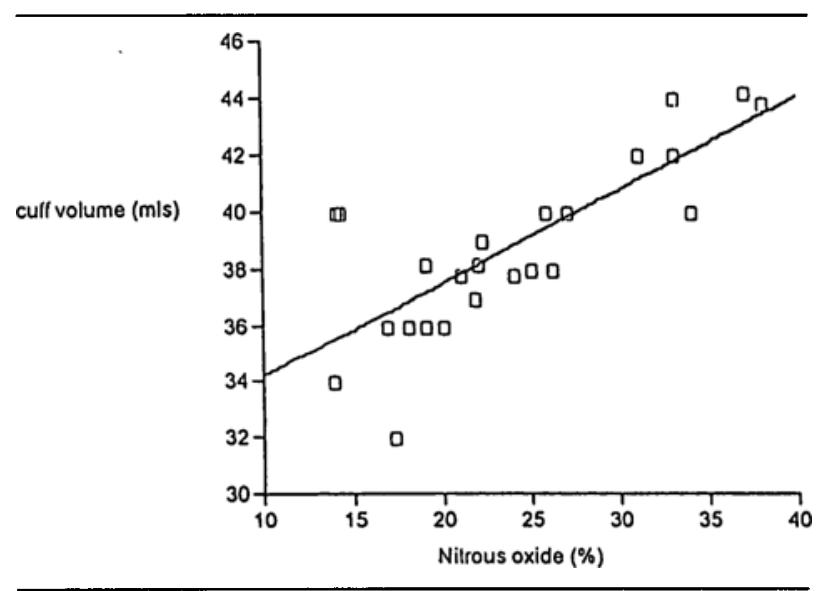

FIGURE 4 Relationship between nitrous oxide concentration and cuff volume. $\mathrm{R}^{2} 0.603, P<0.001$.

nitrous oxide concentration rose through $20 \%$ at $60 \mathrm{~min}$ to $33 \%$ at $120 \mathrm{~min}$ and mean cuff volume was $37 \mathrm{ml}$ at $60 \mathrm{~min}$ and $42 \mathrm{ml}$ at $120 \mathrm{~min}$.

Postoperative follow up of 19 patients revealed three cases of mild sore throat. There were no cases of hoarseness or dysphagia. There was no evidence of regurgitation or aspiration in this series. The mean (range) nasopharyngeal temperature at the start and end of the procedure was $36.8(0.3)$ and $36.6(0.2)^{\circ} \mathrm{C}$ respectively.

\section{Discussion}

Nitrous oxide readily diffuses into air-filled spaces in the body and items of equipment such as pulmonary artery flotation catheters and tracheal tube cuffs. The subsequent increase in volume and pressure is caused by nitrous oxide and to a lesser extent gas warming. Increasing the temperature of $30 \mathrm{ml}$ of gas from 20 to $37^{\circ} \mathrm{C}$ will only increase its volume by $1.74 \mathrm{ml}$. The characteristics for large volume air-filled tracheal tube cuffs are a linear 
increase in pressure for the first three hours of $\mathrm{N}_{2} \mathrm{O}$ / $\mathrm{O}_{2}$ anaesthesia. ${ }^{6}$ This current study demonstrates that the LMA cuff behaves differently: cuff pressure changes are non-linear and the pressure rise is self-limiting within one to two hours.

The inflation of a cuff in a compliant potential space will have a different effect on wall pressure from inflation within a rigid tube. The tracheal tube (TT) cuff expands within the rigid confines of the tracheal rings and it has been shown that a large reduction in tracheal blood flow occurs at cuff pressures $>20 \mathrm{mmHg}{ }^{7} \mathrm{~A}$ pressure in a tracheal cuff $>50 \mathrm{mmHg}$ for only $15 \mathrm{~min}$ can destroy columnar epithelium and will partially denude the basement membrane. ${ }^{8}$ The relationship between mucosal pressure and LMA cuff pressure is more complex. Unlike the trachea, the pharynx is a highly distensible structure which is normally subject to large transient pressure changes and distortion under many physiological conditions. Also the cuff itself generates considerable pressure. The relationship between cuff and mucosal pressure has been studied by Marjot who showed that there was an initial increase in calculated transmitted pharyngeal mucosal pressure, followed by a plateau phase and a decrease by the end of anaesthesia. ${ }^{2}$ Our study has shown a $38 \mathrm{mmHg}$ increase in cuff pressure from in vitro to initial in vivo values and confirms that a counter pressure is being exerted on the LMA cuff by the pharyngeal wall following insertion. The mean final cuff volume and pressure in vivo was $39 \mathrm{ml}$ and $201 \mathrm{mmHg}$ respectively and it is interesting to note from the pressure-volume curve (Figure 2) that mean in vitro cuff pressure at $39 \mathrm{ml}$ was only $180 \mathrm{mmHg}$. This decrease suggests that, as anaesthesia progresses, there is either a reduction in pharyngeal counter pressure and hence pharyngeal mucosal pressure, or an alteration of the physical characteristics of the cuff, or both.

Pharyngeal morbidity is low following LMA anaesthesia and there has been only one reported case of mucosal damage. ${ }^{9}$ The incidence of laryngeal damage is also much reduced with the LMA compared with a TT since placement involves no laryngeal penetration. ${ }^{10,11}$ The incidence of sore throat is approximately $10 \%,{ }^{12-14}$ but this is usually mild, may not be directly related to the LMA, and is less than that reported for the TT (30-40\%) and similar to the face mask (15-22\%). ${ }^{15}$ Other pharyngeal complications potentially related to the LMA are hoarseness $(0-12 \%)^{16,17}$ and dysphagia (4\%). ${ }^{16}$ Lumb and Wrigley suggested that damage might occur by compression of parts of the pharynx against surrounding tissues such as the hyoid bone or cervical vertebrae. ${ }^{1}$ To avoid pharyngeal mucosal damage either pharyngeal mucosal pressure must be lower than calculated values, or the pharyngeal mucosa must be resistant to ischaemic damage, or adaptation of the pharyngeal blood vessels must occur, either due to the uneven distribution of pressure exerted by the LMA, or to a redistribution of blood flow.

There is no evidence that the LMA damages the pharynx over prolonged periods. Operations of more than six hours duration have resulted in no adverse pharyngeal sequelae. ${ }^{18,19}$ In addition, several authors have noted incidentally the use of the LMA for between three and five hours and did not report any associated problems. ${ }^{17,20-22}$

It is generally considered that once the LMA is in situ, ${ }^{4}$ and the cuff inflated, the position remains stable. ${ }^{23,24}$ Overinflation of the cuff can lead to displacement and there has been one report of acute cuff overinflation leading to airway obstruction. ${ }^{25}$ During an eight-hour operation the position of the LMA remained unchanged as judged by fibreoptic laryngoscopy. ${ }^{19}$

In summary, this current study demonstrates that a gradual increase in cuff pressure over a one-to-two-hour period during $\mathrm{N}_{2} \mathrm{O} / \mathrm{O}_{2}$ anaesthesia does not cause displacement of the LMA and that the cuff pressure increase is self-limiting within this time frame. There remains no evidence to suggest that monitoring and controlling cuff pressures is beneficial or that there is an increase in pharyngeal morbidity or adverse airway events during prolonged procedures with the LMA.

\section{Acknowledgments}

We would like to thank P. Tucker and the theatre staff at Cairns Base Hospital for assisting in this project.

\section{References}

1 Lumb $A B$, Wrigley $M W$. The effect of nitrous oxide on laryngeal mask cuff pressure. In vitro and in vivo studies. Anaesthesia 1992; 47: 320-3.

2 Marjot $R$. Pressure exerted by the laryngeal mask airway cuff upon the pharyngeal mucosa. Br J Anaesth 1993; 70: 25-9.

3 Thomson SJ, Healy M, Littlejohn IH. Nitrous oxide and laryngeal mask cuff pressure (Letter). Anaesthesia 1992; 47: 815.

4 Brain AIJ. The Intavent laryngeal mask - instruction manual. London: Intavent, 1991.

5 Brimacombe J, Berry A. A proposed fibre-optic scoring system to standardize the assessment of laryngeal mask airway position (Letter). Anesth Analg 1993; 76: 457.

6 Revenäs $B$, Lindhold $C$. Pressure and volume changes in tracheal tube cuffs during anaesthesia. Acta Anaesthesiol Scand 1976; 20: 321-6.

7 Seegobin RD, van Hasselt GL. Endotracheal cuff pressure and tracheal mucosal blood flow: endoscopic study of effects of four large volume cuffs. BMJ 1984; 288: 965-8.

8 Joh SJ, Matsura H, Kotani Y, et al. Change in tracheal 
blood flow during endotracheal intubation. Acta Anaesthesiol Scand 1987; 31: 300-4.

9 Marjot $R$. Trauma to the posterior pharyngeal wall caused by a laryngeal mask airway (Letter). Anaesthesia 1991; 46: 589-90.

10 Harris TM, Johnston DF, Collins SRC, Heath ML. A new general anaesthetic technique for use in singers: the Brain laryngeal mask airway versus endotracheal intubation. Journal of Voice 1990; 4: 81-5.

11 Lee SK, Hong KH, Choe H, Song HS. Comparison of the effects of the laryngeal mask airway and endotracheal intubation on vocal function. Br J Anaesth 1993; 71 : 648-50.

12 McCrirrick A, Ramage DTO, Pracilio JA, Hickman JA. Experience with the laryngeal mask airway in two hundred patients. Anaesth Intensive Care 1991; 19: 256-60.

13 Alexander $C A$, Leach $A B$. Incidence of sore throats with the laryngeal mask (Letter). Anaesthesia 1989; 44: 791.

14 Reddy SVG, Win N. Brain laryngeal mask - study in 50 spontaneously breathing patients. Singapore Med J 1990; 31: 338: 40.

15 Latto IP. The cuff. In: Latto IP, Rosen M (Eds.). Difficulties in Tracheal Intubation. London: Bailliere Tindal, 1984; 48-74.

16 Brimacombe $J$, Berry $A$. Insertion of the laryngeal mask airway - a prospective study of four techniques. Anaesth Intensive Care 1993; 21: 89-92.

17 Maltby JR, Loken RG, Watson NC. The laryngeal mask airway: clinical appraisal in 250 patients. Can $J$ Anaesth 1990; 37: 509-13.

18 Brimacombe JR. Laryngeal mask anaesthesia and recurrent swallowing. Anaesth Intensive Care 1991; 19: 275-6.

19 Brimacombe J, Shorney $N$. The laryngeal mask airway and prolonged balanced regional anaesthesia. Can J Anaesth 1993; 40: 360-4.

20 Brain AIJ, McGhee TD, McAteer EJ, Thomas A, AbuSaad MAW, Bushman $J A$. The laryngeal mask airway. Development and preliminary trials of a new type of airway. Anaesthesia 1985; 40: 356-61.

21 Miranda AF, Reddy SVG. Controlled ventilation with Brain laryngeal mask. Med J Malaysia 1991; 45: 65-9.

22 Brain AIJ. The development of the laryngeal mask - a brief history of the invention, early clinical studies and experimental work from which the laryngeal mask evolved. Eur J Anaesthesiol 1991; 4: 5-17.

23 Brimacombe $J$, Berry $A$. The flexible, reinforced tube LMA - initial experience (Letter). Anaesth Intensive Care 1993; 21: 379.

24 Johnston DF, Wrigley SR, Robb PJ, Jones HE. The laryngeal mask airway in paediatric anaesthesia. Anaesthesia 1990; 45: 924-7.

25 Welsh BE, Martin DW. Will we ever learn? (Letter). Anaesthesia 1990; 45: 892. 